\title{
Nucleation Controlled in the Aggregative Growth of Strontium Carbonate Microcrystals
}

\author{
B. Sree dhar ${ }^{1}$, Ch. Satya Vani ${ }^{2}$, D. Keerthi Devi ${ }^{1}$, V. Sreeram ${ }^{3}$, M. V. Bas aveswara Rao ${ }^{3, *}$ \\ ${ }^{1}$ Inorganic and Physical Chemistry Division, Indian Institute of Chemical Technology (Council of Scientific and Industrial Research), \\ Hyderabad, 500607, Andhra Pradesh, India \\ ${ }^{2}$ Department of Chemistry, SR International Institute of Technology, Rampally, Keesara (M), RR District, 501301, Andhra Pradesh, India \\ ${ }^{3}$ Department of Chemistry, Krishna University, Machilipatnam, 521001, Andhra Pradesh, India
}

\begin{abstract}
The in fluence of PABA( $p$-a minobenzoicacid) and HEEDTA (N-(2-hydro xyethyl) ethylenediamine- N, N, Ntriacetic acid) on Strontionite crystals via simple $\mathrm{CO}_{2}$ diffusion route is described. The results showed that the experimental parameters have great influence on the shape evolution of products. The presence of templating species and varied $\mathrm{pH}$ are the key primary conditions for the growth morphology. Spike like crystals self assembled in the form of flower like and cauliflower shaped cluster with high crystallin ity were identified. The crystals undergo an interesting morphology changes and have been characterized by X-ray diffraction (XRD), Scanning Electron Microscopy (SEM) and Fourier transform infrared spectroscopy (FT-IR) techniques.
\end{abstract}

Keywords Biomaterials, Composite Materials, Crystal Growth, Electron Microscopy, $p$-amino Benzoic Acid, N-(2hydro xyethyl) Ethylenediamine-N, N', N"- Triacetic Acid

\section{Introduction}

The ability to manipulate the morphogenesis of materials through chemical synthesis is an important requirement of modern materials [1] chemistry, due to the fact that shape, dimension, and size of materials have great influence on their physico-chemical properties and their related applications. Among the variety of morphologies, self-assembled structures have been extensively studied due to their potential applications in various nanodevices[2,3]. However, only a few groups have examined synthetic methods that lead to assembled $\mathrm{SrCO}_{3}$ structures. Literature reports shows that, surfactants or templates, need to be disposed for obtaining pure sample[4,5]. Therefore, it is still a challenge to develop simple and reliable synthetic methods for the synthesis of self-assembled structures.

Strontium carbonate $\left(\mathrm{SrCO}_{3}\right)$ is widely used starting material of strontium for preparing a variety of strontium compounds, [6-8]. This has two traditional main applications. An additive in the production of glass for color television tubes and constituent of ferrite magnets[9,10]. In recent years, researchers have found additional applications of $\mathrm{SrCO}_{3}$ in other fields. Zhang and co-workers[11] discovered nanosized $\mathrm{SrCO}_{3}$-based chemilu minescence sens or showing high selectivity to ethanol and no response to foreign

* Corresponding author:

vbrmandava@yahoo.com (M.V.Basaveswara Rao)

Published online at http://journal.sapub.org/materials

Copyright (C) 2012 Scientific \& Academic Publishing. All Rights Reserved substances, such as gasoline,ammonia and hydrogen. Sreedhar et al synthesized $\mathrm{SrCO}_{3}$ hierarchical structure by natural materials[12] and organic additives[13]. Different $\mathrm{SrCO}_{3}$ hierarchical structures, such as flower -like[14], bundle-like, dumbbell-like, hexagonal star-like[15, 16], branch-like[17], especially spherical or sphere-like[14-16, 18,] rods, wh iskers and ellipsoids,[19] fibers,[20] have been prepared using different methods, including reverse micelles,[21] solvothermal methods[22] liquid-liquid interfaces[23]. Though the methods are encouraging there is considerable scope for further study to improve the quality. $\mathrm{SrCO}_{3}$ microstructures, have attracted extraordinary attention due to their novel applications as sensors having chemilumenescence[24], catalyst[25, 26], color television tubes, chief constituent of ferrite magnets [27].

$\mathrm{We}$ are reporting the successful synthesis of $\mathrm{SrCO}_{3}$ structures of spike like and cauliflower shaped morphology, efficiently achieved by using two organic additives- PABA and HEEDTA with simple $\mathrm{CO}_{2}$ gas flow diffusion technique.

\section{Experimental}

\subsection{Materials}

Para-a minobenzoicacid $\left(\mathrm{C}_{7} \mathrm{H}_{7} \mathrm{O}_{2} \mathrm{~N}\right)$, N-(2hydro xyethyl) ethylenediamine- $\mathrm{N}, \mathrm{N}^{\mathrm{I}}, \mathrm{N}^{\mathrm{II}}$-triaceticac id $\quad\left(\mathrm{C}_{10} \mathrm{H}_{18} \mathrm{O}_{7} \mathrm{~N}_{2}\right)$, Ammonium carbonate $\left(\mathrm{NH}_{4}\right)_{2} \mathrm{CO}_{3}$, sodium hydroxide $(\mathrm{NaOH})$ and strontium chloride $\left(\mathrm{SrCl}_{2}\right)$ were of analytical grade and used without further purification. Double distilled water was used in all experiments. 


\subsection{Char acterization}

X-ray diffraction measurements of the strontium carbonate hierarchial structures were recorded using a Rigaku diffracto meter ( $\mathrm{Cu}$ radiation, $\lambda=0.1546 \mathrm{~nm}$ ) running at $40 \mathrm{kV}$ and $40 \mathrm{~mA}$ (Tokyo, Japan). FT -IR spectra of $\mathrm{SrCO}_{3}$ structures were recorded with a Thermo Nicolet Nexus (Washington, USA) 670 spectrophotometer. Crystals were collected on a round cover glass $(1.2 \mathrm{~cm})$, washed with deionized water and dried in a desiccator at room temperature. The cover glass was then mounted on a SEM stub and coated with gold for SEM analysis.

\subsection{Preparation of $\mathrm{SrCO}_{3}$ Microcrystals}
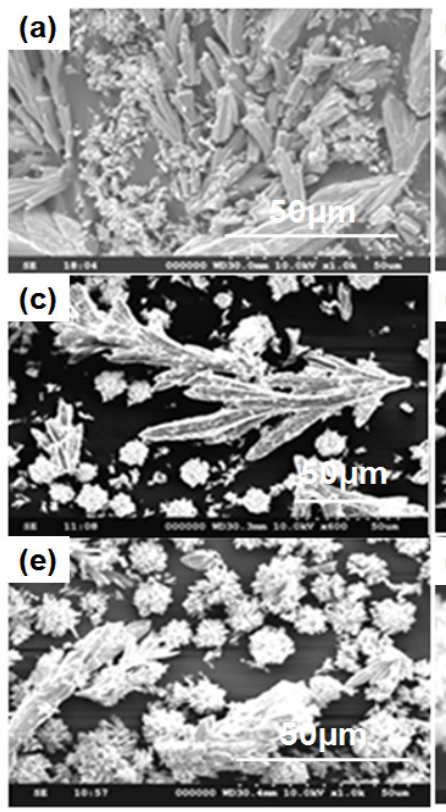

A typical procedure for preparation of crystalline $\mathrm{SrCO}_{3}$ crystals was carried out as follows: In a g las s bottle $2.5 \mathrm{mmol}$ $\mathrm{SrCl}_{2}, 0.1 \mathrm{mmol}$ PABA/HEEDTA were dissolved in $20 \mathrm{~mL}$ water and was stirred continuously to ensure complete solubility. Then the $\mathrm{pH}$ of the solution was adjusted to 7.0 and 10.0 by using $0.1 \mathrm{M} \mathrm{NaOH}$. After that the prepared solution was then covered with parafilm which was punched with three needle holes and placed in larger desiccator containing freshly crushed ammonium carbonate $(20 \mathrm{~g})$ at the bottom. After $24 \mathrm{hr}$ crystallization, the parafilm was removed and the white precipitate deposited on the glass bottle centrifuged and washed thoroughly with distilled water, followed by ethanol and allowed to dry at room temperature for further crystallization.
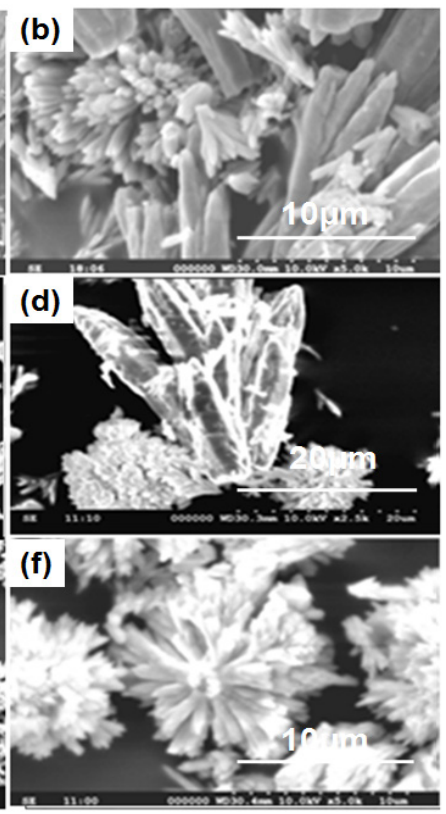

Figure 1. $\mathrm{SEM}$ images of $\mathrm{SrCO}_{3}$ in the presence of PABA at varied $\mathrm{pH}$ conditions (a,b) pH 3.0, (c, d) pH 7.0, and (e, f) pH 10.0

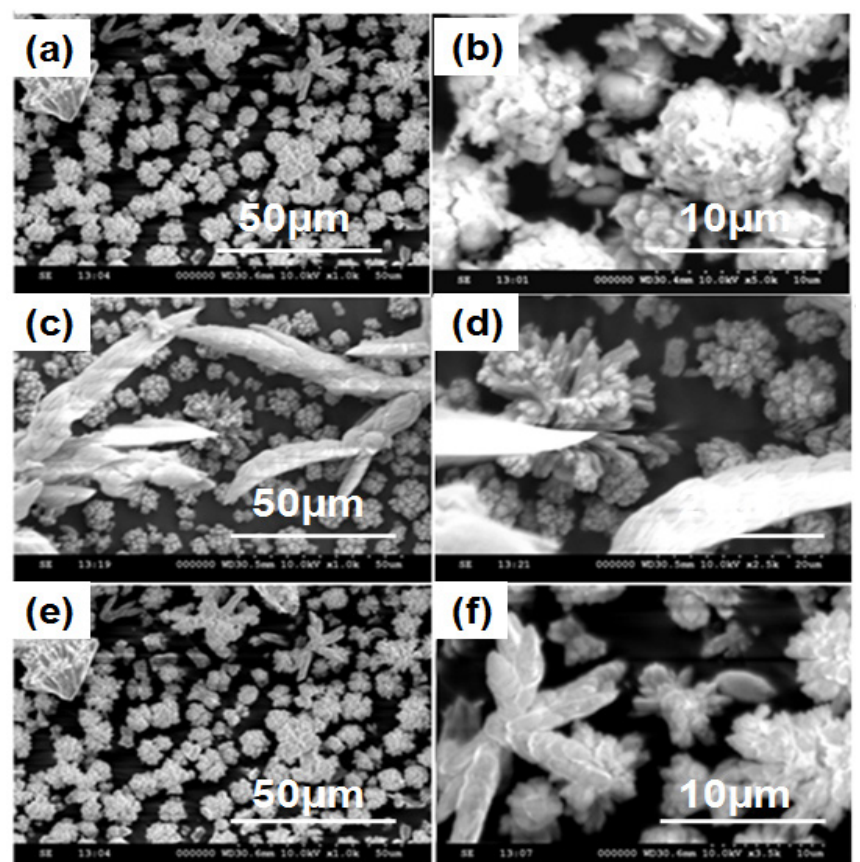

Figure 2. $\mathrm{SEM}$ images of $\mathrm{SrCO}_{3}$ in the presence of HEEDTA at varied $\mathrm{pH}$ conditions (a, b) initial pH 3.0, (c, d) pH 7.0, and (e, f) $\mathrm{pH} 10.0$ 


\section{Results and Discussion}

\subsection{Effect of Additives on the Mor phology of $\mathrm{SrCO}_{3}$}

Significant changes in the morphologies were observed when the $\mathrm{pH}$ of the reaction conditions varied between 7 and 10. Figure 1 and 2 shows the SEM images of $\mathrm{SrCO}_{3}$ structures by adding the additives PABA and HEEDTA at different $\mathrm{pH}$ conditions. In general $\mathrm{SrCO}_{3}$ dendrimers are obtained in the absence of additive[12], while in the presence of PABA at initial $\mathrm{pH} 3.0$, indiv idual spike like crystals were observed (Figure 1a, b). When the $\mathrm{pH}$ of the reaction mixture was increased to 7 , the individual spikes aggregates to coniform like structures (Figure 1c, d). On further increasing the $\mathrm{pH}$ to 10.0 , the spikes aggregates more closely and self assembled into flower like structures (Figure 1e, f). Figure 2a shows the $\mathrm{SEM}$ images of $\mathrm{SrCO}_{3}$ structures in the presence of the additive HEEDTA. Remarkable changes in the morphology was observed with this additive and the shape of $\mathrm{SrCO}_{3}$ structures changed from dendrimeric to cauliflower bunch like structures with short spikes of subunits having smooth surface at in itial pH 3 (Figure $2 \mathrm{a}, \mathrm{b}$ ). At neutral $\mathrm{pH}$ mixed phase of cau liflower bunches with rough surface and spadix shaped structures with fibre like units are identified (Figure 2c, d). At pH 10.0, morphology of the $\mathrm{SrCO}_{3}$ structures appears similar to that observed at $\mathrm{pH} 3$ with rough surface (Figure $2 \mathrm{e}, \mathrm{f}$ ). The strontianite crystals clearly aggregates into cauliflower bunch like and coniform structures in $\mathrm{CO}_{2}$ diffusion route. To the best of our knowledge, such close packed aggregates of strontionite crystals have not been observed in other biomimetic approaches to the growth of $\mathrm{SrCO}_{3}$ crystals.

\subsection{Structur al Characterization of $\mathrm{SrCO}_{3}$ Microcrystals}

The XRD pattern of the isolated solids could be indexed to that orthorhombic structure of strontium carbonate and all the peaks are assigned by using JCPDS (05-418). The results implied that the aggregation did not alter the phase structure of $\mathrm{SrCO}_{3}$.To our expectation, the crystallinity nature of the product was sensitive to that $\mathrm{pH}$ conditions. At lower $\mathrm{pH}$ condition showed a greater crystallinity than the product prepared under higher $\mathrm{pH}$ condition, implying the influence of solution $\mathrm{pH}$ on the crystallinity. In Figure 3 the pattern of $\mathrm{SrCO}_{3}$ crystals obtained in aqueous solution displays the following diffraction peaks with (hkl) indices (110), (111), (021), (002), (121), (200), (130), (220), (040), (032), (041), (202), (132), (141) respectively. Similarly in figure 4 , the diffraction peaks with (hkl) indices (110), (111), (021), (002), (121), (200), (112), (220), (032), (040), (132), and (113), of pure orthorhombic strontionite respectively. It may also be seen that the peak (111) is the strongest, suggesting that $\mathrm{SrCO}_{3}$ crystals obtained in aqueous solution grow mainly along with the (111) phase.

\subsection{FTIR Studies}

To identify the growth mechanism and the effect of PABA and HEEDTA on $\mathrm{SrCO}_{3}$ microstructures, the sample was analyzed by FT-IR spectroscopy. The sharp peaks at 856 , $703 \mathrm{~cm}^{-1}$ (Figure $5 \mathrm{a}$ ), 855, $701 \mathrm{~cm}^{-1}$ (Figure $5 \mathrm{~b}$ ) and 857, $701 \mathrm{~cm}^{-1}$ (Figure $5 \mathrm{c}$ ) are in-plane and out-plane bending of $\mathrm{CO}_{3}{ }^{2-}$

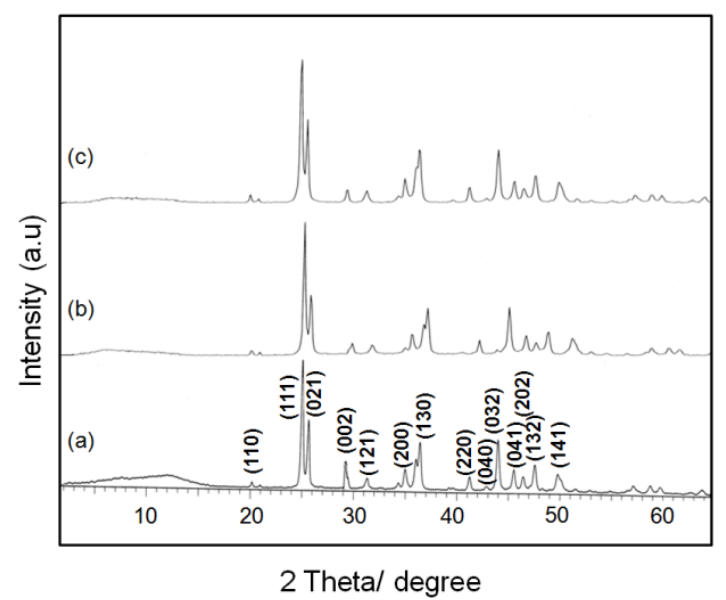

Figure 3. XRD pattern of $\mathrm{SrCO}_{3}$ in the presence of $\mathrm{PABA}$ (a) initial $\mathrm{pH}$ 3.0, (b) $\mathrm{pH} 7.0$, and (c) $\mathrm{pH} 10.0$

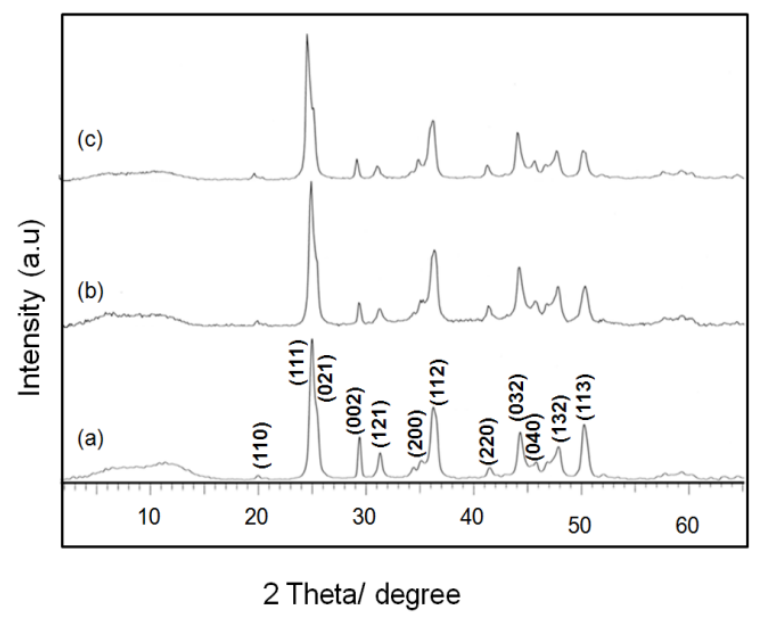

Figure 4. XRD pattern of $\mathrm{SrCO}_{3}$ in the presence of HEEDTA (a) initial $\mathrm{pH} 3.0$, (b) $\mathrm{pH} 7.0$, and (c) $\mathrm{pH} 10.0$

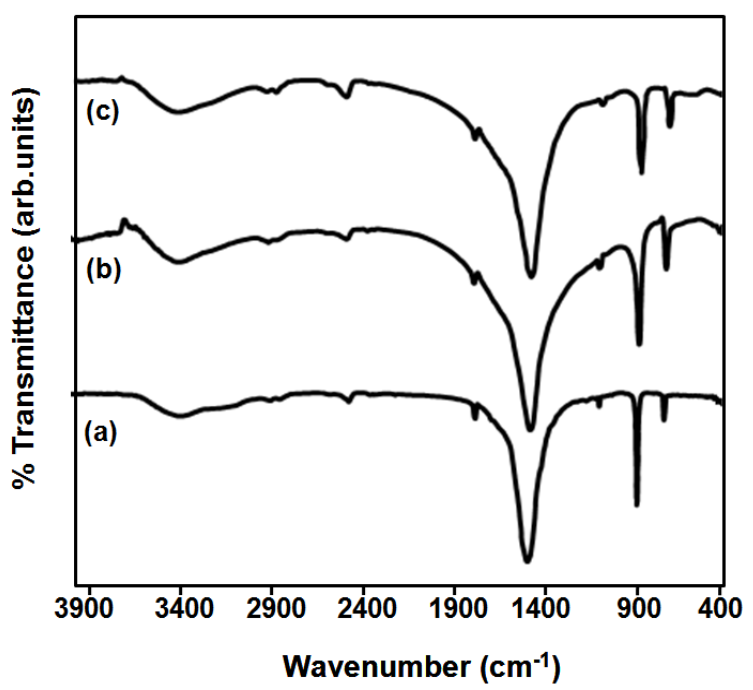

Figure 5. FT-IR of $\mathrm{SrCO}_{3}$ microstructures nucleated (a) in the absence of an additive, (b) presence of PABA and (c) presence of HEEDTA 
The IR bands at 1476,1469 and $1465 \mathrm{~cm}^{-1}$ (Figure $5 \mathrm{a}, \mathrm{b}, \mathrm{c}$ ) correspond to the asymmetric stretching mode of $\mathrm{C}-\mathrm{O}$ bond while the weak band at $1074 \mathrm{~cm}^{-1}$ (Figure $5 \mathrm{~b}, \mathrm{c}$ ) is attributed to the symmetric $\mathrm{C}-\mathrm{O}$ stretching vibration. The band at 3418 $\mathrm{cm}^{-1}$ (Figure $5 \mathrm{~b}$ ) can be attributed to $\mathrm{OH}$ stretching vibration due to hydrogen bonding and or $\mathrm{N}-\mathrm{H}$ stretch of the $-\mathrm{NH}_{2}$ group from the functional groups present in additives. The band at $3423 \mathrm{~cm}^{-1}$ (Figure $5 \mathrm{c}$ ) can be attributed to $\mathrm{OH}$ stretching vibration due to hydrogen bonding and or $\mathrm{N}-\mathrm{H}$ stretch of the $-\mathrm{NH}_{2}$ group from the functional groups present in additive

In comparison with Figures $5 \mathrm{~b}$, the $\mathrm{C}-\mathrm{O}$ stretching vibration peak around $1465 \mathrm{~cm}^{-1}$ in Figure $5 \mathrm{c}$, shifts to higher frequency by $4 \mathrm{~cm}^{-1}\left(1469 \mathrm{~cm}^{-1}\right)$, suggesting that PABA and HEEDTA have different influence of $\mathrm{SrCO}_{3}$. This is probably due to the fact that the two organic molecules can adsorb onto the different planes of $\mathrm{SrCO}_{3}$ nuclei and influence the mode of crystal growth, resulting in little change of microstructure.

\section{Conclusions}

In summary, uniform hierarchical $\mathrm{SrCO}_{3}$ complex structures in the form of spike like and cauliflower bunch like units were efficiently obtained by a facile ammonium carbonate method in the presence of PABA and HEEDTA as additives. The present uniform hierarchical $\mathrm{SrCO}_{3}$ structures were self assembled by the related crystalline particles, assisted by the additives would enlarge the potential applications of strontium carbonate microstructures. This strategy may also be expected for the preparation of other metal carbonates.

\section{REFERENCES}

[1] S. Mann., The Chemistry of Form, Angew. Chem. Int. Ed. 2000, 39(19), 3392-3406

[2] A.P. Alivisatos, Semiconductor Clusters, Nanocrystals \& Quantum Dots,Science. 1996,271(5251), 933-37.

[3] L.S.Zhong, J.S.Hu, H.P.Liang, A.M.Cao, W.G.Song, and L.J.Wan., 2006, Self-Assembled 3D Flower like Iron Oxide Nanostructures and Their Application in Water Treatment,Adv.Mater.18, 2426-2431.

[4] T.K.Sau and C.J.Murphy., 2005, Self-Assembly Patterns Formed upon Solvent Evaporation of Aqueous Cety ltrimethylammoniumBromide-Coated Gold Nanoparticles of Various Shapes,Langmuir. 21(7),2923-2929.

[5] H. C. Zeng and B. Liu., 2004, Mesoscale Organization of $\mathrm{CuO}$ Nano ribbons: Formation of "Dandelions, J. Am. Chem. Soc. 126(26), 8124-8125.

[6] M. Akiyama, C. N. Xu, K. Nonaka and T. Watnabe., 1998, Intense visible light emission from Sr3A12O6:Eu, Dy,Appl. Phys. Lett. 73, 3046-3049.
[7] M. Akiy ama, C. N. Xu, Y. Liu, K. Nonaka, and T. Watnabe., 2002, Influence of $\mathrm{Eu}$, Dy Co-doped strontium aluminate composition on mechanoluminescence intensity, J.Lumin. 97(1), 13-18.

[8] Z. L. Tang, F. Zhang, Z. T. Zhang, C. Y. Huang, and Y. H. Lin., 2000, Luminescent properties o $\mathrm{SrAl}_{2} \mathrm{O}_{4}$ : Eu, Dy material prepared by the gel method, J.Eur. Ceram. Soc. 20, (12), 2129-2132.

[9] J. Massone., 1983, Technology and uses of barium and strontium compounds. In Coope, M. B., Clarke, G.M., Eds.; 5th Industrial Minerals Int. Cingr. (Madrid, Spain, 1982); Metal Bulletin: London, 115.

[10] Roskill. 1989, The Economics of Strontium 1989, 5th ed.; Roskill Information Services: London, UK.

[11] J. J. Shi, J. J. Li, Y. F. Zhu, F. Wei, and X. R. Zhang, 2002, Nanosized $\mathrm{SrCO}_{3}$-based chemiluminescence sensor for ethanol, Anal. Chim. Acta, 466(1), 69-78.

[12] B. Sreedhar, Ch. Satyavani, D. Keerthi Devi, C. Rambabu, M. V. Basaveswara Rao, and M. Saratchandra Babu., 2011, Bioinspired Synthesis of Morphologically Controlled $\mathrm{SrCO}_{3}$ superstructures by natural gum acacia, Crystal Research Technology. 46(5), 485-492.

[13] Ch.Satya vani, M. Sarat Chandra babu, K. Balakrishna, and C. Rambabu., 2010, Influence of Vitamin $\mathrm{B}_{3}$ on Morphosynthesis of $\mathrm{CaCO}_{3}, \mathrm{BaCO}_{3}$ and $\mathrm{SrCO}_{3} \mathrm{Micro}$ and Nano Structures, Journal of Metallurgy and Materials Science, 52 (4) $351-356$

[14] M. G. Ma, and Y. J. Zhu, 2007, A Simple Route to Synthesis of $\mathrm{SrCO}_{3}$ with Olive-Like and Flower-Like Morphologies, J. Nanosci. Nanotech. 7(12), 4552-4556.

[15] J. Yu, H. Guo, and B. Cheng, 2006Shape evolution of SrCO3 particles in the presence of poly-(styrene-alt-maleic acid) J. Solid. State. Chem. 179, 800-803.

[16] M. X. Zhang, J. C. Huo, Y. S. Yu, C. P. Cui, and Y. L. Lei, 2008, Morphology Control of $\mathrm{SrCO}_{3}$ Crystals using Complexons as Modifiers in the Ethanol-water mixtures, Chin. J. Struct. Chem. 27(10), 1223-1229

[17] M. G. Ma, and Y. J. Zhu, 2008, Microwave synthesis of $\mathrm{SrCO}_{3}$ one-dimensional nanostructures assembled from nanocry stals using ethy lenediamine additive, Mater. Lett. 62, 2512-2515.

[18] I. Sondi and E. Matijević, 2003, Homogeneous Precipitation by Enzyme-Catalyzed Reactions. 2. Strontium and Barium Carbonates , Chem. Mater. 15(6), 1322-1326.

[19] M. H. Cao, X. L. Wu, X. Y. He, and C. W. Hu, 2005, Microemulsion mediated solvothermal synthesis of $\mathrm{SrCO}_{3}$ nanostructures, Langmuir. 21(13), 6093-6096.

[20] M. Balz, H. A. Therese, M. Kappl, L. Nasdala, W. Hofmeister, H. J. Butt, and W. Tremel., 2005, Morphosynthesis of strontianite nanowires using polyacry late templates tethered onto self-assembled monolayers, Langmuir. 21(9), 3981-3986.

[21] G. S. Guo, F. B. Gu, Z. H. Wang, H. Y. Guo., 2005, Low-temperature growth of single-crystal $\mathrm{SrCO}_{3}$ nano needles, Chin. Chem. Lett. 16(8), 1101-1104.

[22] L. G. Shi, and F. L. Du., 2007, Solvothermal synthesis of $\mathrm{SrCO}_{3}$ hexahedral ellipsoids, Mater. Lett. 61(14-15), 3262-3264. 
[23] S. Reddy, D. Rautaray, S. R. Sainkar, M. Sastry., 2003,Morphology of $\mathrm{SrCO}_{3}$ crystals grown at the interface between two immiscible liquids, Bull. Mater. Sci. 26 (3), $283-288$.

[24] J. J. Shi, J. J. Li, Y. F. Zhu, F. Wei, and X. R. Zhang, 2002, Nanosized $\mathrm{SrCO}_{3}$-based chemiluminescence sensor for ethanol, Anal. Chim. Acta. 466, 69-78.

[25] K. Omata, N. Nukui, T. Hottai, Y. Showa, and M. Yamada, 2004, Strontium carbonate supported cobalt catalyst for dry reforming of methane under pressure, Catal. Commun. 5, 755-758.

[26] L. Wang and Y. F. Zhu. 2005, Effects of Nanostructure on Catalytic Degradation of Ethanol on $\mathrm{SrCO}_{3}$ Catalysts, J. Phys.Chem. B 109(11), 5118-5123.

[27] A. Roskill, The Economics of Strontium, 5th ed. (Roskill Information Services, London, UK, 1989). 